\title{
Palmoplantar Pustulosis in Electronic Cigarette Users: A Potential for Concern
}

\author{
Vidhatha Reddy Tina Bhutani \\ Department of Dermatology, University of California San Francisco (UCSF), San Francisco, CA, USA
}

Palmoplantar pustulosis (PPP) is a chronic dermatosis that presents as multiple, small, hyperkeratotic or pustular lesions predominantly affecting the palms and soles. Numerous studies have demonstrated a significant association between smoking and the development of PPP, with one cohort study finding that up to $95 \%$ of PPP patients had a history of smoking or were smoking at the time of PPP onset [1]. Evidence also suggests that smoking cessation in conjunction with medical management may improve symptoms in PPP patients when compared to those who receive medical management alone [2].

Tobacco smoking is known to modulate the function of various inflammatory mediators including, but not limited to, impaired neutrophil chemotaxis and adhesion, overproduction of reactive oxygen species and proteolytic enzymes by macrophages, and diminished cytotoxic activity and cytokine production in natural killer cells [3]. Nicotine stimulates neutrophils to produce IL-8, leading to leukocytosis in tobacco smokers. It is also known to concentrate in the sweat glands of smokers. Given that PPP predominantly affects eccrine sweat glands, nicotine may play a role in both increased susceptibility to and pathogenesis of PPP in smokers. This is supported by immunohistochemical studies of PPP patients, which have found destruction of the acrosyringium in eccrine sweat glands $[1,4]$. When compared to palmar skin from both smokers without PPP and healthy

\section{KARGER}

(c) 2019 S. Karger AG, Basel

E-Mail karger@karger.com

www.karger.com/drm nonsmokers, PPP lesions in smokers have demonstrated an abnormal expression of the $\alpha-7$ subunit of keratinocyte nicotinic acetylcholine receptors, which is responsible for terminal differentiation of keratinocytes [4]. Impaired terminal differentiation of keratinocytes surrounding eccrine sweat glands results in the disruption of skin homeostasis, which may be the inciting pathologic process that leads to PPP development.

This is particularly concerning given the dramatic rise of electronic cigarette (referred to as e-cigarettes, vapes, or by their commercial names, i.e., JUUL) usage in recent years. Nicotine absorption from smoking one conventional cigarette ranges from 0.3 to $2 \mathrm{mg}$, with the increase in blood nicotine levels ranging from an average of 15 to $30 \mathrm{ng} / \mathrm{mL}$ [5]. A review of twelve studies analyzing the nicotine absorption rate in e-cigarette users found increases in blood nicotine levels to be comparable to those of traditional tobacco cigarettes [6]. One study for example, found that following a 10-puff standardized session, plasma nicotine levels increased in subjects by $16.4 \mathrm{ng} /$ $\mathrm{mL}$ on average [7]. Thus, for diseases such as PPP that may be directly influenced by nicotine exposure, the comparable exposure to nicotine in both e-cigarettes and traditional tobacco products warrants attention. In current dermatologic practice, patients are routinely asked about history of smoking and utilization of other tobacco products. However, given the concern for nicotine's role in 
PPP, it is imperative that e-cigarette use be documented during work-up for PPP. In addition, further studies are needed to observe rates of PPP in e-cigarette users in comparison to traditional tobacco users to elucidate whether the pathogenesis of PPP is related more so to nicotine exposure itself or to a multifactorial impact from exposure to tobacco and other chemicals in traditional tobacco products.

\section{Key Message}

The association between palmoplantar pustulosis and smoking may be mediated via nicotine exposure, which raises concern that palmoplantar pustulosis may also be associated with electronic cigarette use.

\section{Disclosure Statement}

Dr. Bhutani is a principal investigator for studies funded by Janssen, Merck, Celgene, and Regeneron. She is also an advisor for AbbVie and Eli Lilly.

\section{Funding Sources}

No funding sources were utilized for the preparation of this paper.

\section{Author Contributions}

Both authors contributed to the development of this paper.

\section{References}

1 Eriksson MO, Hagforsen E, Lundin IP, Michaëlsson G. Palmoplantar pustulosis: a clinical and immunohistological study. Br J Dermatol. 1998 Mar;138(3): 390-8.

2 Armstrong AW, Harskamp CT, Dhillon JS, Armstrong EJ. Psoriasis and smoking: a systematic review and meta-analysis. Br J Dermatol. 2014 Feb;170(2):304-14.

3 Gonçalves RB, Coletta RD, Silvério KG, et al. Impact of smoking on inflammation: Overview of molecular mechanisms. Inflamm Res. 2011;60(5):409-24.
4 Hagforsen E, Edvinsson M, Nordlind K, Michaëlsson G. Expression of nicotinic receptors in the skin of patients with palmoplantar pustulosis. Br J Dermatol. 2002 Mar;146(3):383-91.

5 Walley SC, Wilson KM, Winickoff JP, Groner J. A public health crisis: electronic cigarettes, vape, and JUUL. Pediatrics. 2019 Jun; 143(6):e20182741.

6 National Academies of Sciences, Engineering, and Medicine; Health and Medicine Division; Board on Population Health and Public Health Practice; Committee on the Review of the Health Effects of Electronic
Nicotine Delivery Systems. Eaton DL, Kwan LY, Stratton K, editors. Public Health Consequences of E-Cigarettes. Washington (DC): National Academies Press (US); 2018. Available from: https://www.ncbi. nlm.nih.gov/books/NBK507191/.

7 Spindle TR, Breland AB, Karaoghlanian NV, Shihadeh AL, Eissenberg T. Preliminary results of an examination of electronic cigarette user puff topography: the effect of a mouthpiece-based topography measurement device on plasma nicotine and subjective effects. Nicotine Tob Res. 2015 Feb;17(2):142-9. 